\title{
A Hybrid Dry and Aqueous Fractionation Method to Obtain Protein-Rich Fractions from Quinoa (Chenopodium quinoa Willd)
}

\author{
Geraldine Avila Ruiz ${ }^{1}$ - Anke Arts ${ }^{2} \cdot$ Marcel Minor $^{1} \cdot$ Maarten Schutyser $^{2}$
}

Received: 18 December 2015 / Accepted: 14 April 2016/Published online: 4 May 2016

(C) The Author(s) 2016. This article is published with open access at Springerlink.com

\begin{abstract}
Combination of dry and aqueous fractionation is investigated to obtain protein-rich fractions from quinoa in a milder and more sustainable way compared to conventional wet fractionation. Dry fractionation of quinoa involved milling and subsequent air classification, generating a protein-enriched embryo fraction. Subsequently, this fraction was milled, suspended, and further fractionated by aqueous phase separation. The efficiency of aqueous phase separation could be improved by addition of $\mathrm{NaCl}(0.5 \mathrm{M})$. Finally, the top aqueous phase was decanted and ultrafiltered, resulting in a protein purity of $59.4 \mathrm{w} / \mathrm{dw} \%$ for the $0.5 \mathrm{M} \mathrm{NaCl}$-protein solution and a protein yield (gram protein obtained/gram protein in seed) of $62.0 \%$. Having used $98 \%$ less water compared to conventional wet extraction, the hybrid dry and aqueous fractionation is a promising method for industry to create value from quinoa in a more economic and sustainable friendly way while minimizing the impact on quinoa's native protein functionality.
\end{abstract}

Keywords Quinoa protein · Hybrid fractionation · Protein yield $\cdot$ Protein purity $\cdot$ Wet fractionation

\section{Introduction}

The nutritional properties of quinoa are unique since it contains all essential amino acids, trace elements, and vitamins

Maarten Schutyser

Maarten.Schutyser@wur.nl

1 Food and Biobased Research, Wageningen University and Research Centre, P.O. Box 17, 6700 AA Wageningen, Netherlands

2 Laboratory of Food Process Engineering, Wageningen University, P.O. Box 17, 6700 AA Wageningen, Netherlands
(B6, folate, riboflavin, and niacin) (Abugoch 2009). As a result, its popularity and cultivation area are expanding rapidly. A promising quinoa variety to use on a large scale is sweet quinoa (virtually saponin-free). This variety could be a more sustainable and economic raw material to use in industry due to savings in post-harvest processing (not necessary to remove saponins), in seed transport, and availability (it can be cultivated in different regions and also in temperate climates) (Avila Ruiz et al. 2016b).

To stimulate more extensive use and create added value of (sweet) quinoa in the production of foods, ingredients derived from quinoa by fractionation have been explored by several studies, in particular, the production of protein isolates (Brinegar and Goundan 1993; Brinegar et al. 1996; Chauhan et al. 1999; Aluko and Monu 2003; Lindeboom 2005; Abugoch et al. 2008; Aora and Alvarado 2009; Valenzuela et al. 2013; Föste et al. 2015; Avila Ruiz et al. 2016a, b). In all these studies, the conventional wet fractionation method was applied. It involves the use of a solvent for fat removal (hexane, petroleum ether, etc.), an alkali to solubilize the protein from the defatted flour (mostly $\mathrm{NaOH}$ ) and an acid to purify the protein via precipitation (mostly $\mathrm{HCl}$ ). However, this method consumes large amounts of water and energy and moreover often leads to denaturation of the protein (Schutyser and van der Goot 2011).

Dry fractionation is milder and more sustainable for production of protein concentrates from cereals (wheat, barley, etc.) and legumes (pea, lupine, chickpea, etc.), although generally, the purities obtained are less high (Tyler et al. 1981; Wu and Stringfellow 1992; Pelgrom et al. 2013a). A major advantage of this technique is that native functional properties of the proteins are retained (Pelgrom et al. 2015a). Dry fractionation involves fine milling of the seeds to disclose protein-rich particles and subsequent dry separation of the flour in fractions of different particle size using air classification. The dissociation 
of seed components is critical to enable separation and is dependent on seed structure and the milling conditions.

For pea seeds $(23.7 \mathrm{w} / \mathrm{dw} \%$ protein $)$, dissociation of protein bodies from starch granules can be achieved by very fine impact milling, which is followed by air classification, generating a protein-rich fine fraction $(55.6 \mathrm{w} / \mathrm{dw} \%$ protein) with smaller particle size and a starch-rich course fraction with a larger particle size (Pelgrom et al. 2015b). For quinoa seeds ( $\sim 15 \mathrm{w} / \mathrm{dw} \%$ protein), it is extremely difficult to separate protein bodies from starch granules as these are similar in size (Prego et al. 1998). However, quinoa protein bodies are concentrated in the embryo of the seed $(\sim 23.5 \mathrm{w} / \mathrm{dw} \%$ protein), while starch granules are concentrated in the perisperm (Ando et al. 2002). Therefore, we propose rotor milling followed by sieving or air classification to dissociate and separate the embryo from the perisperm. Using rotor milling, we aim at clear dissociation of embryo and perisperm, and in this way, we can produce protein-enriched fractions with either sieving or air classification.

Attempts to further dry fractionate the embryo fraction into higher protein-enriched fractions were hitherto unsuccessful, because protein bodies and starch granules in the quinoa seed are similar in size (Lindeboom 2005). To achieve higher protein purities, wet fractionation may be applied. However, a hybrid method of dry fractionation and aqueous phase separation, followed by ultrafiltration, is investigated here. This approach is inspired by successful aqueous phase separation of dry-enriched pea fractions and is reported milder and more sustainable (Pelgrom et al. 2015a; Schutyser et al. 2015). The dissolution and subsequent centrifugation of the pea fine fraction obtained by air classification provided a phase separated system with four layers, where the protein was concentrated in the top two layers. Via this method, pea protein purity could be increased from $49.7 \mathrm{w} / \mathrm{dw} \%$ in the fine fraction to $68.6 \mathrm{w} /$ $\mathrm{dw} \%$ in the combined two top layers. After ultrafiltration, a final protein purity of $77.4 \mathrm{w} / \mathrm{dw} \%$ could be achieved.

The aim of this study was thus to develop a hybrid separation process for quinoa to obtain high protein-rich fractions. The novelty of this method consists especially of the combination of dry fractionation and aqueous fractionation for obtaining protein-rich quinoa fractions, which, to the best of our knowledge, has not been done before. Purity and yield were evaluated at every step of the new proposed hybrid separation process. Finally, the hybrid fractionation route is compared to the conventional wet fractionation of quinoa for its efficiency.

\section{Material and Methods}

\section{Materials}

Quinoa seeds (Chenopodium quinoa Willd) of the sweet variety Atlas were supplied by the Agricultural Research Institute
(INIA), Santiago, Chile. Sodium chloride was obtained from Sigma Aldrich Chemie GmbH, Schnelldorf, Germany. Deionized water was used throughout the fractionation process.

\section{Milling of Quinoa Seeds and Air Classification of Quinoa Flour}

Quinoa seeds were milled using a 100 UPZ Rotor Mill (Hosokawa-Alpine, Augsburg, Germany) with an airflow of $40 \mathrm{~m}^{3} / \mathrm{h}$ and a built-in sieve with a screen aperture of $2.0 \mathrm{~mm}$. These optimal settings were derived from previous unpublished work. The obtained flour was air classified using an ATP50 Classifier (Hosokawa-Alpine, Augsburg, Germany) with a classifier wheel speed of $1000 \mathrm{rpm}$ and an airflow of $80 \mathrm{~m}^{3} / \mathrm{h}$. The fine fraction from this air classification step is in this study referred to as the non-milled fraction. This is because the majority of the generated embryo-rich fine fraction from the air classification step was further milled using a ZPS50 Impact Mill (Hosokawa-Alpine, Augsburg, Germany) with an airflow of $52 \mathrm{~m}^{3} / \mathrm{h}$ and a classifier wheel speed of $2500 \mathrm{rpm}$ to facilitate dissolution of the protein. The extra impact milling was applied to facilitate disclosure of the protein-rich components from the surrounding matrix and thus subsequent dissolution during suspension.

\section{Aqueous Phase Separation of the Fine and Coarse Quinoa Fractions}

The milled and non-milled fine fractions obtained by air classification were further fractionated by aqueous phase separation. Suspensions of the fine fractions $(20 w / w \%)$ were prepared in deionized water with and without the addition of $\mathrm{NaCl}(0.15,0.35$, and $0.5 \mathrm{M})$. They were stirred for $3 \mathrm{~h}$ at room temperature and subsequently centrifuged for $30 \mathrm{~min}$ at 4500 rpm (Pelgrom et al. 2015a).

\section{Ultrafiltration of the Liquid Layer of the Phase-Separated Fractions}

The liquid layers of the phase-separated impact-milled fine fractions with $0,0.15$, and $0.5 \mathrm{M} \mathrm{NaCl}$ were carefully decanted and utrafiltered at room temperature using an Amicon Ultrafiltration Cell with a regenerated cellulose membrane (PLBC, Ultracel PL Membrane, NMWL cutoff of $3 \mathrm{kDa}$; Millipore Corporation, Billerica, MA, USA). A pressure of $350 \mathrm{kPa}$ was applied for approximately $165 \mathrm{~min}$. This ultrafiltration time was slightly varied to obtain enough permeate volume. The average permeability during the experiments was $0.11 \mathrm{~L} \mathrm{~m}^{-2} \mathrm{~h}^{-1}$ bar $^{-1}$, which is not very high due to the continuous increasing component concentrations in the batch process. 


\section{Determination of the Particle Size Distribution}

To determine the particle size distributions of the milled and non-milled quinoa seeds, a Mastersizer 2000 equipped with a Scirocco 2000 dry dispersion unit (Malvern Instruments, Worcestershire, UK) was used. All measurements were performed in duplicate.

\section{Image Analysis}

Scanning electron micrographs (SEMs) were obtained using a Phenom Pure G2 desktop scanning electron microscope (Eindhoven, the Netherlands).

\section{Determination of Protein Purity and Protein Yield}

Protein purity was defined as mass protein/mass dry matter $(\mathrm{w} / \mathrm{dw} \%)$ and corresponds to the term "protein content" used in the literature mentioned in the present study. To determine the protein content (mass protein) of a sample, the Dumas method was used. Nitrogen content was measured using a Nitrogen Analyzer (FlashEA 1112 series, Thermo Scientific, Interscience, Breda, the Netherlands). The conversion factor used to convert nitrogen to protein was 5.7 (Chauhan et al. 1992). All measurements were performed in duplicate.

The protein yield after each step in the fractionation process was calculated as follows:

Protein yeild $(\%)=\frac{\% \text { protein purity of fraction } \times \mathrm{g} \text { fraction }}{\% \text { protein purity of starting material } \times \mathrm{g} \text { starting material }} \times 100 \%$

\section{Determination of Starch Purity}

Starch purity was defined as the ratio of mass starch and mass dry matter (w/dw\%) and determined using the Total Starch Assay Kit (Megazyme International Ireland Ltd., Bray, Ireland). All measurements were performed in duplicate.

\section{Statistical Analysis}

Error bars for all data points were calculated by taking the standard deviation of the average value of duplicates. If the error bars of two data points did not overlap, we concluded they were significantly different.

\section{Results and Discussion}

\section{Milling and Air Classification}

Quinoa seeds were milled using a rotor mill with an airflow of $40 \mathrm{~m}^{3} / \mathrm{h}$ and a sieve screen aperture of $2.0 \mathrm{~mm}$. The objective of the milling was to separate the protein-rich embryo from the protein-poor perisperm. SEM was performed to assess the efficiency of the milling. In the SEM pictures, it can be observed that the rotor milling has the potential to achieve neat dissociation of the embryo from the perisperm (Fig. 1). Particle size analysis showed a decrease in the volume fraction of particles of around $1000 \mu \mathrm{m}$ and an increase in the volume fraction of particles of 100-600 $\mu \mathrm{m}$ (Fig. 2a). This change in particle size distribution also reflects the dissociation of quinoa seed into smaller perisperm and embryo particles. However, the broadening of the particle size distribution after milling indicated that dissociation of the embryo from the perisperm was not complete. Instead of rotor milling, also, roller milling might be applied. In a previous unpublished study, in our laboratory, this was investigated and it was concluded that rotor milling of quinoa seeds provides better results in terms of complete disclosure than roller milling. It is assumed that predominant shear and low compression forces applied by the rotor mill dissociates the embryo, while most of the perisperm remains intact. In comparison, the roller milling applies high compression forces, which provide also dissociation of the embryo but at the same time lead to more breakage of the perisperm particles.

The air classification of the milled quinoa flour produced a coarse perisperm-rich fraction and a fine embryo-rich fraction (Table 1 and Fig. 2b). As the protein content of the quinoa embryo $(23.5 \mathrm{w} / \mathrm{dw} \%)$ is higher than that of the perisperm $(7.2 \mathrm{w} / \mathrm{dw} \%)$, the fractionation resulted in almost a doubling of the protein purity in the fine fraction, with a factor five times higher protein yield than in the coarse fraction. The cut size characterizes the air classification process by defining the size where particles have equal chance of ending up in either the coarse or fine fraction. Because the yield of both fractions is equal, the cut size is comparable to the mass median diameter of the quinoa seed after milling $(704.5 \mu \mathrm{m})$.

\section{Aqueous Phase Separation}

As observed for pea fractionation, it was hypothesized that aqueous suspension of quinoa flour would lead to phase separation of protein, starch, and fiber into soluble and insoluble fractions. This phase separation can be explained by differences in density between non-dissolved particles and possible enthalpic and entropic effects between different dissolved biopolymers (Pelgrom et al. 2015a). However, for quinoa, it was 
Fig. 1 After impact milling of the quinoa seeds, a perisperm hull (magnification $\times 180$ ) and $\mathbf{b}$ embryo particle (magnification $\times 160$ )

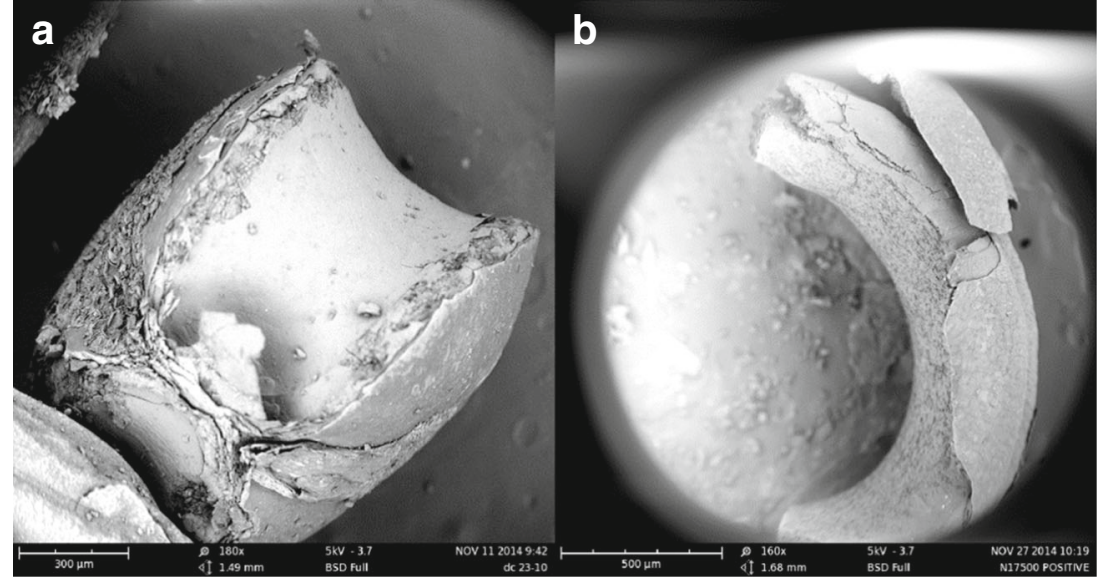

found that an additional fine milling step was critical to facilitate protein dissolution and would thus increase enrichment of dissolved protein by subsequent aqueous phase separation. In this fine milling step, the average particle diameter decreased from 559 down to $30 \mu \mathrm{m}$.

When suspending the non-milled and milled fine fractions, phase separation into three distinct layers, a liquid layer (layer 1), a white solid layer (layer 2), and a beige solid layer (layer 3), was observed for both fractions (Fig. 3). Layer 1 had the highest protein purity in both fractions, showing protein enrichment in the top layer at either particle size (Fig. 4). However, protein purity and protein yield were higher in layer 1 of the finely milled fine fraction $(41.2 \mathrm{w} / \mathrm{dw} \%$ and $40.3 \%$, respectively) compared to the non-milled fraction, indicating enhanced protein dissolution. This can be explained by the disruption of cells upon milling and thus the easier dissociation of starch granules and protein bodies during suspension.

The quinoa protein consists of $35 \%$ water-soluble albumins and $37 \%$ globulins soluble in salt solutions (Abugoch 2009), while from the experiments, it appeared that the dissolved (only water) protein in the top layer presents $40.3 \%$ of all proteins (Fig. 4). This might at least be partially explained by the quinoa variety being higher in water-soluble protein.

Previous research on quinoa protein showed that protein solubility could be increased by the addition of salt (Brinegar and Goundan 1993). It was observed that when adding up to $0.5 \mathrm{M} \mathrm{NaCl}$ to quinoa flour suspensions, protein yield increased steadily. Higher $\mathrm{NaCl}$ concentrations did not increase the yield significantly. Therefore, we added $\mathrm{NaCl}$ to the suspensions of the milled fine fraction to reach different concentrations in the range of $0-0.5 \mathrm{M}$. Similar to those observed for the suspensions without salt addition, the suspensions phase was separated into three layers; however, the dry matter content of the top layer increased with increasing salt concentration (Fig. 5). Protein purity and protein yield of the layers were calculated by correcting for the added salt. For layer 1, the protein yield increased considerably from 40.3 to $80.3 \%$ going from 0 to $0.5 \mathrm{M} \mathrm{NaCl}$, respectively (Fig. 6). The protein purity in the same layer did not increase as strongly with increased salt content, but it was higher for 0.35 and $0.5 \mathrm{M} \mathrm{NaCl}$ than for 0 and $0.15 \mathrm{M} \mathrm{NaCl}$. These results indicate higher protein solubility at higher salt concentrations and are line with the findings from literature. The increased protein solubility can be explained by the salting in-effect (Arakawa and Timasheff 1982; Collins 1997; Li and Mu 2011). The added salt ions interact with the charged groups of the protein molecule, leading to less interactions of the protein molecule with the surrounding water molecule, which results in an increased solubility of the protein.

As $37 \%$ of the quinoa protein is salt-soluble, the addition of salt facilitates the solubilization of globulins, which can be added to the amount of solubilized albumins, as albumin
Fig. 2 Particle size distribution a before and after impact milling of quinoa seeds and $\mathbf{b}$ of the quinoa coarse and fine fractions obtained after air classification a

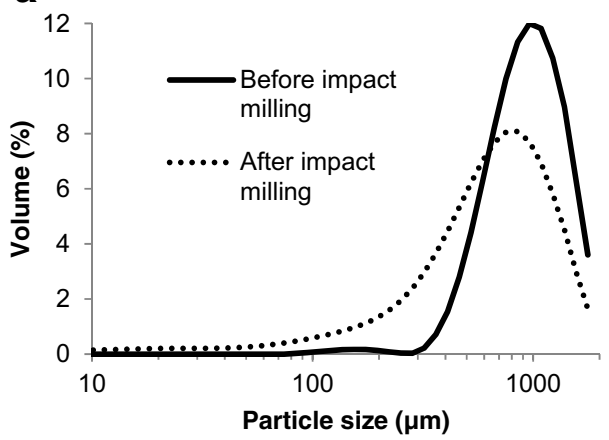

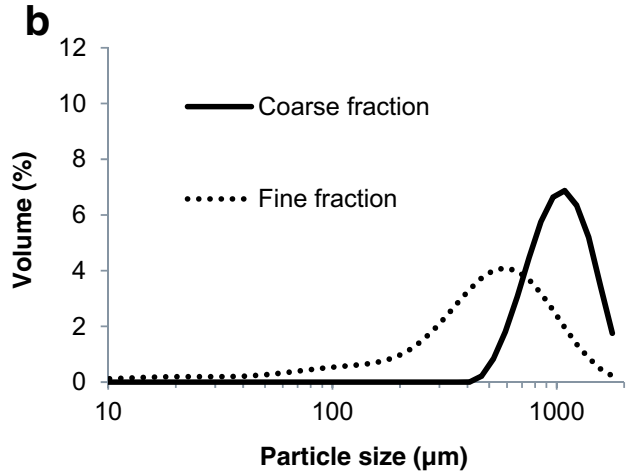


Table 1 Experimental characterization of the whole quinoa flour, the fine fraction and the coarse fraction after air classification, with \pm is equal to the standard deviation

\begin{tabular}{lllllr}
\hline Material & Yield (\%) & $\begin{array}{l}\text { Protein } \\
\text { yield (\%) }\end{array}$ & $\begin{array}{l}\text { Protein purity } \\
(\mathrm{w} / \mathrm{dw} \%)\end{array}$ & $\begin{array}{l}\text { Starch purity } \\
(\mathrm{w} / \mathrm{dw} \%)\end{array}$ & $D_{0.5}(\mu \mathrm{m})$ \\
\hline Whole flour & 100.0 & 100.0 & $14.5 \pm 0.6$ & 53.7 & $996.1 \pm 18.5$ \\
Coarse fraction & $48.3 \pm 1.8$ & 17.1 & $6.6 \pm 3.6$ & 70.6 & $1035.3 \pm 10.5$ \\
Fine fraction & $50.4 \pm 2.5$ & 82.9 & $23.9 \pm 1.3$ & 24.9 & $558.5 \pm 6.2$ \\
\hline
\end{tabular}

dissolution behavior was found not to be affected by the salt content (Brinegar and Goundan 1993). The smaller increase in protein purity compared to protein yield might be due to the additional solubilization of non-protein components. Starch purity did not clearly increase with higher salt concentrations (Fig. 6), which suggests that possibly, the dissolution of soluble fibers might have been influenced by the $\mathrm{NaCl}$ concentration.

\section{Ultrafiltration}

To further increase protein purity, the liquid top layer of the phase-separated suspensions with and without added salt were carefully decanted and subjected to ultrafiltration. The idea behind this step was that small solutes would be removed and proteins would be retained by the membrane, thereby increasing the protein concentration in the retentate. The ultrafiltration was carried out in a batch system for approximately $165 \mathrm{~min}$, after which a retentate volume of $55 \%$, compared to the initial feed volume, was obtained. Because the filtration
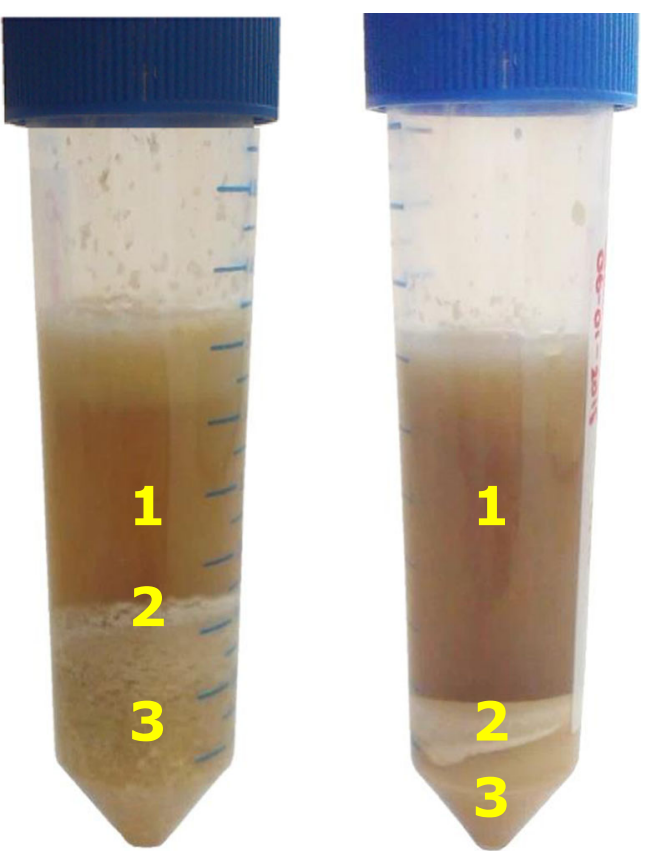

Fig. 3 Aqueous phase separation of the suspended fine fractions with and without milling before suspension. left Non-milled fine fraction $\left(D_{0.5}\right.$ $559 \mu \mathrm{m})$ and right milled fine fraction $\left(D_{0.5} 30 \mu \mathrm{m}\right)$. The numbers indicate the layers formed time was not always exactly 165 min for each sample, small corrections were made to obtain protein purity and protein yield values for an exact final retentate volume of $55 \%$. On the basis of $55 \%$ retentate yield, the protein concentration in the retentate could be increased from 41 to $46 \mathrm{w} / \mathrm{dw} \%$ without addition of salt and from 35 to $59 \mathrm{w} / \mathrm{dw} \%$ for $0.5 \mathrm{M} \mathrm{NaCl}$ (Fig. 7). It should be emphasized that the latter values are the protein contents without correction for the presence of $\mathrm{NaCl}$.

It can be concluded that the protein purity after ultrafiltration increases significantly, which is caused obviously by the loss of salt via the permeate flow. However, the total protein yield also increased, which may be explained by the different
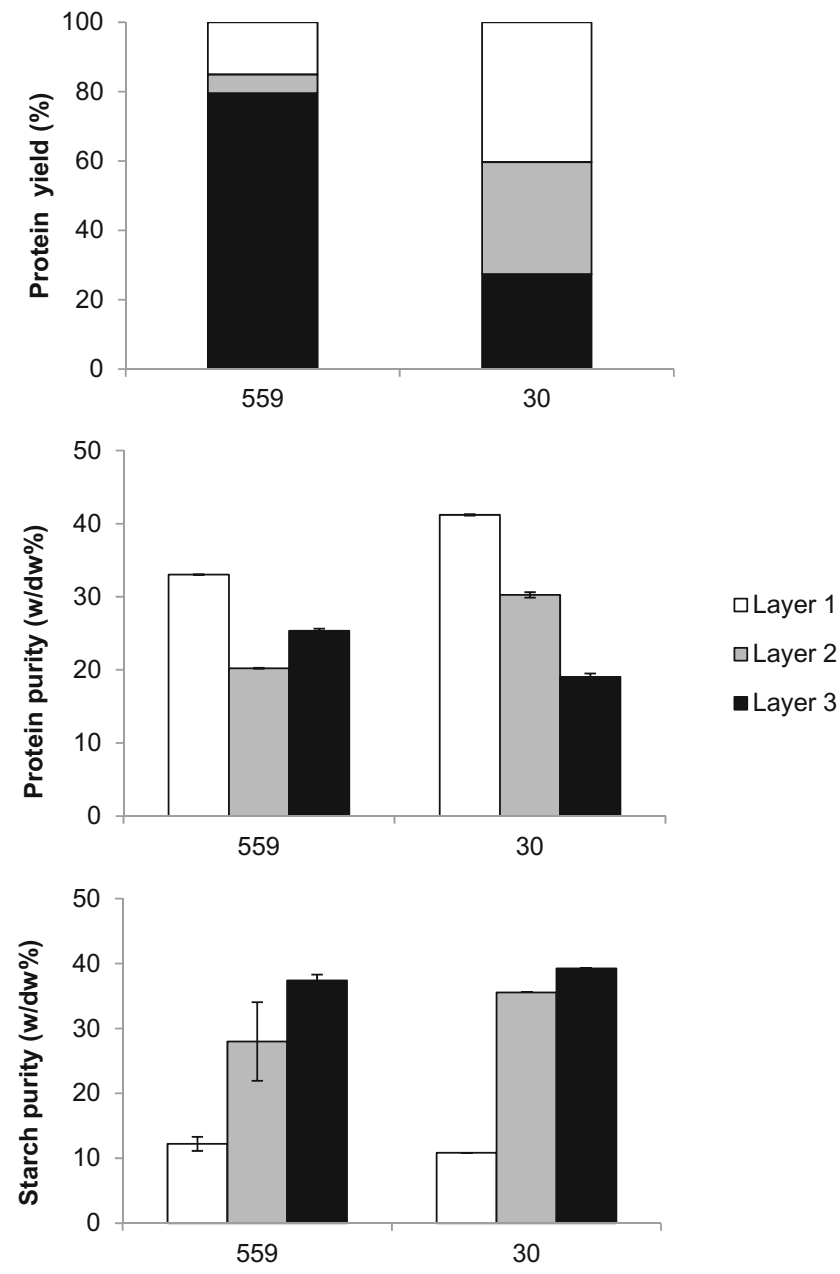

Average particle size of suspended fine fraction $(\mu \mathrm{m})$

Fig. 4 Protein yield (\%), protein purity (w/dw\%), and starch purity $(\mathrm{w} / \mathrm{dw} \%)$ of the non-milled and milled fine fractions 


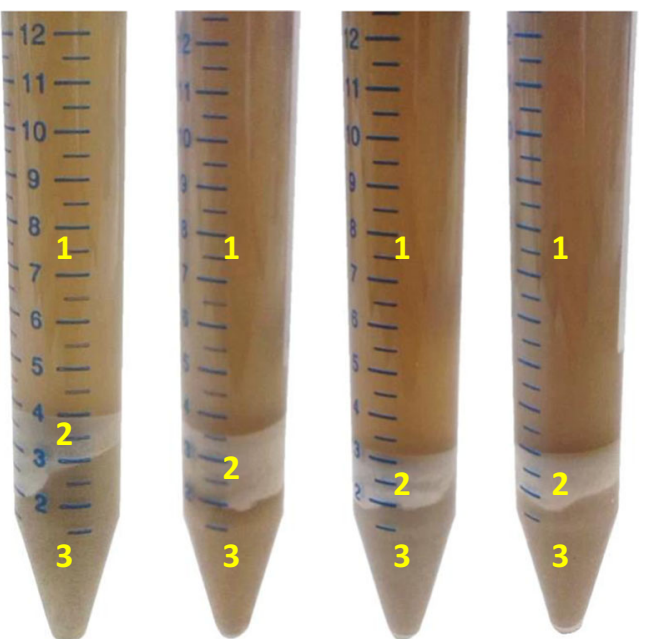

Fig. 5 Aqueous phase separation of the suspended milled fine fraction with varying $\mathrm{NaCl}$ concentrations. Left to right $0,0.15,0.35$, and $0.5 \mathrm{M}$ $\mathrm{NaCl}$. The numbers indicate the layers formed

size of the globulins and albumins. Globulins range from 8 to $100 \mathrm{kDa}$ in size, while albumins are 8-9 kDa in size (Brinegar and Goundan 1993). The cutoff of the ultrafiltration membrane was $3 \mathrm{kDa}$, so some smaller albumins were probably lost during the ultrafiltration. Because at high salt concentrations, there are relative more globulins compared to albumins, the relative loss of protein will substantially decrease at higher salt concentrations. In conclusion, the use of salt during aqueous phase separation and subsequent ultrafiltration is considered very promising as it provides higher protein purity and yield.

\section{Process Review}

A mass flow analysis was carried out and visualized in a Sankey diagram to review the entire hybrid dry and aqueous fractionation process of quinoa. This was specifically done for the aqueous phase separation with $0.5 \mathrm{M} \mathrm{NaCl}$ for extracting protein from the milled fine fraction (Fig. 8). The protein yield and protein purity, which start from the seed to the final ultrafiltration, are shown in Fig. 9. It can be observed that a large amount of material (48.1\%) was lost during the impact milling of the fine fraction (Fig. 8). This material loss can be explained by the relatively small particle size of the fraction, which increases the attractive van der Waals forces between particles and particles and wall of the mill interior, thus resulting in fouling (Pelgrom et al. 2014). However, when feeding larger amounts of material (compared to the $287 \mathrm{~g}$ that was fed during our experiment), the loss due to fouling is expected to be much lesser. This can be explained by the development of a steady state situation during which no further accumulation of material will occur. If we exclude the losses during impact milling, $24.4 \%$ protein from the total quinoa protein could be recovered without salt use in the
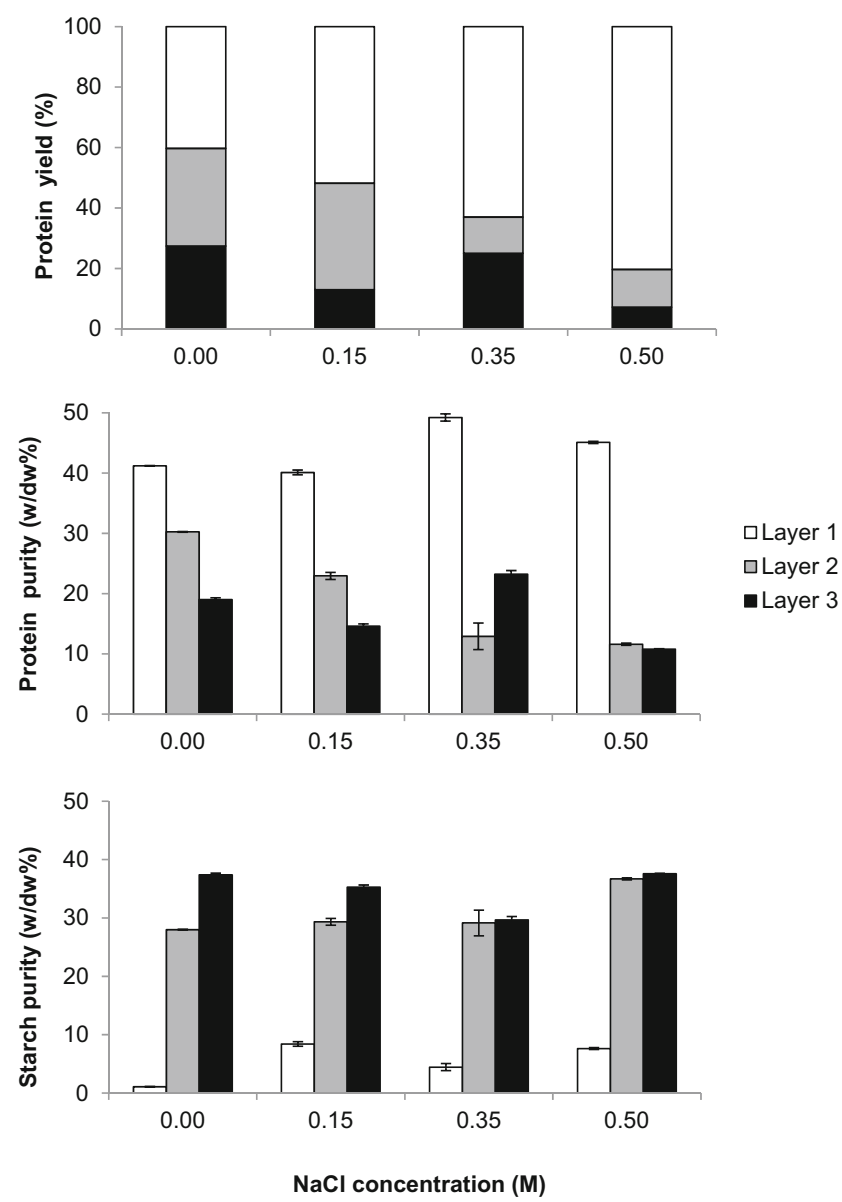

Fig. 6 Protein yield, protein purity (w/dw\%), and starch purity (w/dw\%) of the suspended milled fine fraction with varying $\mathrm{NaCl}$ concentrations

process and $62.0 \%$ with use of $0.5 \mathrm{M} \mathrm{NaCl}$ during aqueous phase separation (Fig. 9).

The proposed hybrid fractionation is a milder and a more sustainable way compared to wet fractionation, although the protein purity obtained is still lower compared to conventional wet fractionation. Further process optimization can be carried out to increase the protein purity even more. Optimizations might be performed from the very beginning, before even milling the seed. A recent study applied a moist conditioning treatment to quinoa before milling (Föste et al. 2015). By raising the moisture content from 12.3 to $15 w / w \%$, the protein purity of the bran fraction obtained after milling increased from 24 to $28 \mathrm{w} / \mathrm{dw} \%$. The higher moisture content was related to increased elasticity of the outer cell tissues, providing better dissociation of the embryo from the perisperm during milling. In another study on pea, the moisture content prior to milling was increased to shift the protein to the rubbery state. This treatment facilitated disentanglement from the glassy starch granules during milling, providing higher separation efficiency (Pelgrom et al. 2013b).

Another step, where the protein purity may be further increased, is during ultrafiltration. One may increase the 
Fig. 7 Protein yield and protein purity $(\mathrm{w} / \mathrm{dw} \%)$ of layer 1 of the phase-separated suspensions containing different salt concentrations
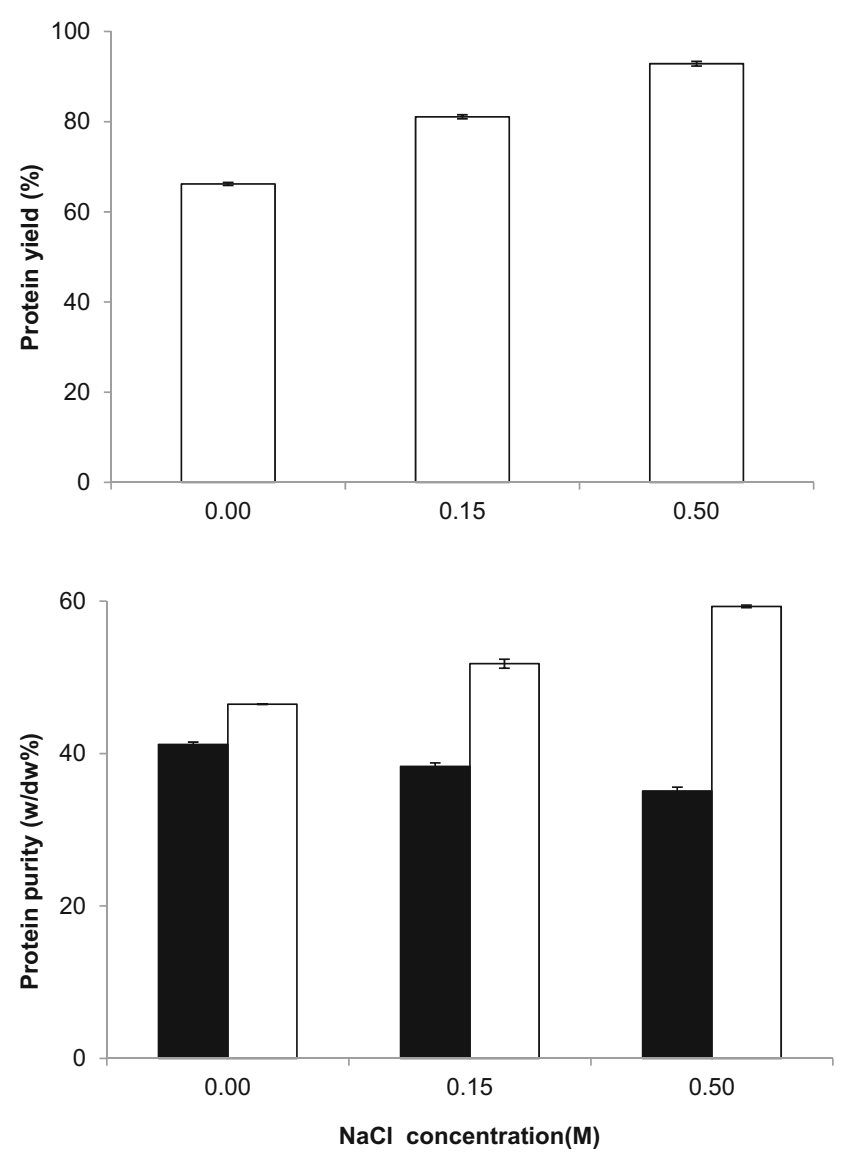

-Before ultrafiltration $\square$ After ultrafiltration concentration factor or apply diafiltration to completely wash out the salt. Increasing the concentration factor leads to a smaller retentate volume. For example, for a final retentate volume of $20 \%$ (in combination with $0.5 \mathrm{M} \mathrm{NaCl}$ ), protein purity may further increase from 59.4 to $78.2 \mathrm{w} / \mathrm{dw} \%$. The drawback of an increased concentration factor is that the permeate flux will decline severely due to the accumulating solute concentration (Suki et al. 1984). For $55 \%$ retentate volume, diafiltration and thereby removal of all salt would increase protein purity from 59.4 to $65.5 \mathrm{w} / \mathrm{dw} \%$, in combination with $0.5 \mathrm{M} \mathrm{NaCl}$ aqueous phase separation. However, removal of the salt will lead to precipitation of the saltsoluble globulins, which may not always be desirable. Still, the calculations show there is room for further optimization of the process toward protein purities that are approaching protein concentrations from conventional wet fractionation.

\section{Comparison to Conventional Wet Fractionation}

To compare the efficiency of the proposed hybrid dry and aqueous fractionation method to conventional fully wet fractionation for protein isolation, protein yield, protein purity, and water consumption were compared with literature data (Table 2). Recent studies have analyzed protein yield and protein purity from quinoa during wet fractionation with varying conditions (Föste et al. 2015; Aora and Alvarado 2009; Avila

Fig. 8 Sankey diagram of the hybrid dry and aqueous fractionation process for the production of protein-rich fractions of quinoa. The arrow thickness corresponds to the mass of the flow. Red protein, dark blue starch, and light blue rest

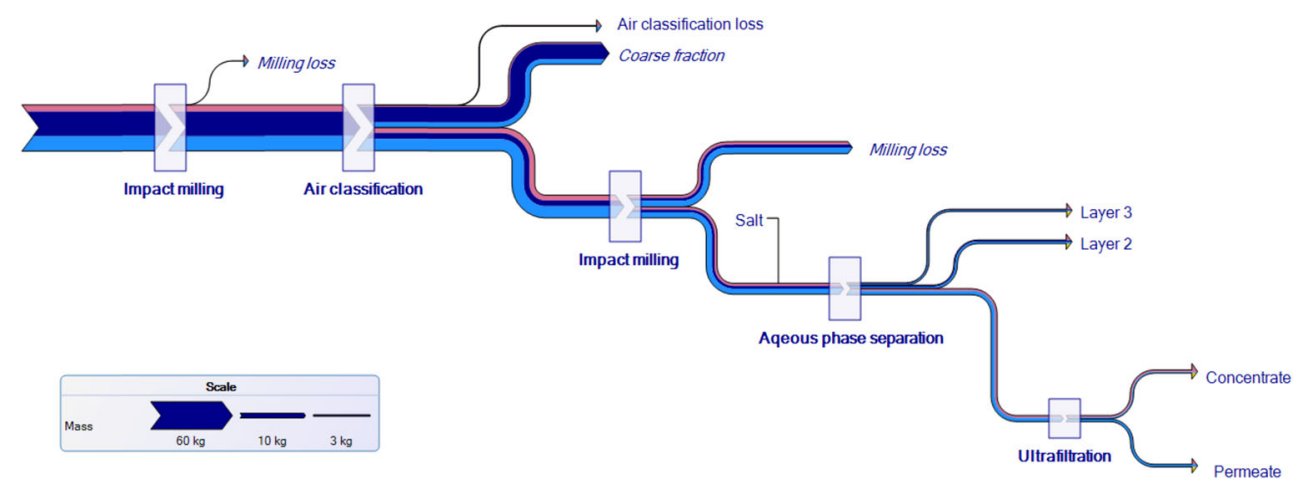


Fig. 9 Protein purity (w/dw\%) and protein yield (gram protein obtained/gram protein in the seed) after each step of the hybrid dry and aqueous fractionation process, assuming that fouling at higher throughputs is negligible

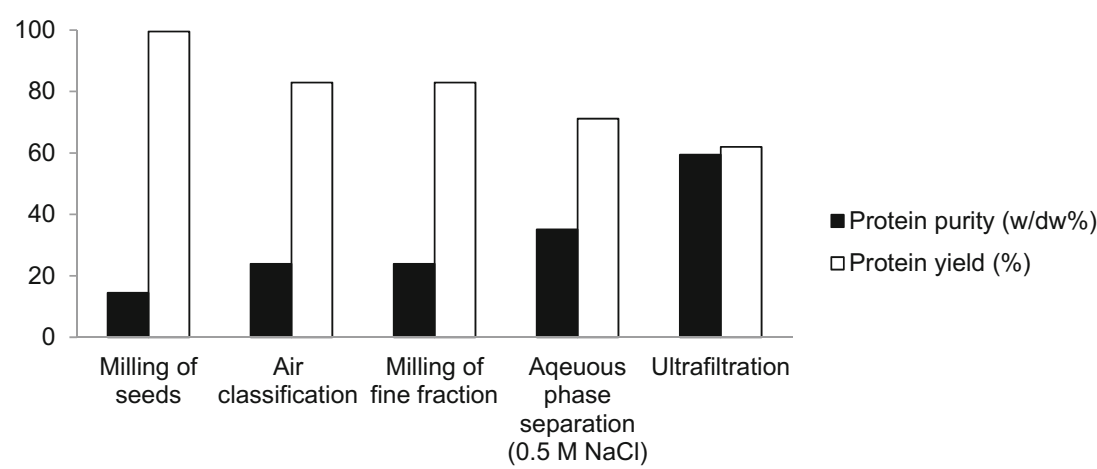

Ruiz et al. 2016b). With wet fractionation, very high protein purities (68-93 w/dw\%) can be achieved but at the expense of a lower protein yield (gram protein obtained/gram protein in the seed; 24-61\%). Furthermore, during wet fractionation, 9$9.5 \mathrm{ml}$ of water was used per gram of quinoa flour (depending on the fat content of the quinoa seeds used) to achieve a protein yield of $61 \%$. The hybrid fractionation process proposed in this study resulted in a lower protein purity compared to the literature values for wet fractionation but similar or higher protein yield compared to wet fractionation. But what is important to note is that only $0.2 \mathrm{ml}$ of water per gram of quinoa flour was used to achieve the protein yield of $62 \%$, which means $97.8 \%$ savings in water compared to wet fractionation. Even if using double the amount of water for ultrafiltration to remove salts remaining in the final quinoa fraction, savings of over $88.9 \%$ in water are possible. This reduction in water consumption is connected to an enormous potential reduction in energy consumption, as less water needs to be removed for drying the final protein ingredient suspension.

Another main difference between our process and the conventional extraction is that mild conditions are used in contrast to wet fractionation (avoiding addition of chemicals for fat extraction and to induce $\mathrm{pH}$ shifts). This is not only more cost-effective for the producer but is also in line with clean label and sustainability trends among consumers. Moreover, by avoiding harsh conditions, the native properties of the quinoa protein are also retained as much as possible. Finally, we recommend exploring the application of the side streams of our hybrid fractionation process to maximize sustainability. Such side streams are, for example, the perisperm starch-rich fraction obtained after air classification and the aqueous phases that are enriched in starch.

\section{Conclusions}

We succeeded in developing a hybrid separation process for quinoa to obtain high protein-rich fractions. The method proposed in the present study can provide a protein concentrate with a purity of $59 \mathrm{w} / \mathrm{dw} \%$ and a protein yield of $61 \%$. This yield is similar or higher compared to conventional wet fractionation. Although the purity is lower compared to conventional extraction with further process optimization, the product obtained is still relevant for the food industry. This is because higher protein purities will not always be required or even desired, as food producers may also wish to keep some of the quinoa fiber, starch, oil, and micronutrients in the protein concentrate for functional or nutritional benefits depending on the application. In this case, the advantages of mild fractionation are obvious in providing reduction in water, energy, and chemical consumption and retention of native functional properties. Finally, we estimated that the protein purity may be further increased up to $78 \mathrm{w} / \mathrm{dw} \%$ by process optimization.

Table 2 Summary of the different methods for isolation of quinoa protein

\begin{tabular}{llllll}
\hline Method for protein isolation & Study & $\begin{array}{l}\text { Protein } \\
\text { solubilization } \\
\text { conditions }\end{array}$ & $\begin{array}{l}\text { Protein } \\
\text { yield (\%) }\end{array}$ & $\begin{array}{l}\text { Protein purity } \\
(\mathrm{w} / \mathrm{dw} \%)\end{array}$ & $\begin{array}{l}\text { Water use } \\
\text { (milliliter per gram of quinoa flour) }\end{array}$ \\
\hline Wet fractionation & Avila Ruiz et al. 2016b & $\mathrm{pH} \mathrm{8-11}$ & $23-36$ & $88-91$ & $21-22$ \\
& Aora and Alvarado 2009 & $\mathrm{pH} \mathrm{7.5-10.5}$ & $37-56$ & $67-79$ & $10-11$ \\
& Scanlin and Stone 2009 (patent) & $\mathrm{pH} \mathrm{8-12}$ & No data & $46-82$ & $10-11$ \\
Dry and wet fractionation & Föste et al. 2015 & $\mathrm{pH} \mathrm{10}$ & 63 & 70 & $10-11$ \\
Dry and aqueous fractionation & Present study & $0-0.5 \mathrm{M} \mathrm{NaCl}$ & $24-62$ & $47-59$ & 0.2 \\
\hline
\end{tabular}

Protein yields were recalculated according to Eq. (1) and using a nitrogen-to-protein conversion factor of 5.7 for fair comparison. Water use was recalculated to milliliter water per gram of non-defatted quinoa flour, assuming an average fat content of 5-7.2\% in the quinoa seed used (Bhargava and Srivastava 2013) 


\section{Compliance with Ethical Standards}

Conflict of Interest The authors declare that they have no conflict of interest.

Open Access This article is distributed under the terms of the Creative Commons Attribution 4.0 International License (http:// creativecommons.org/licenses/by/4.0/), which permits unrestricted use, distribution, and reproduction in any medium, provided you give appropriate credit to the original author(s) and the source, provide a link to the Creative Commons license, and indicate if changes were made.

\section{References}

Abugoch, L. (2009). Chapter 1 quinoa (Chenopodium quinoa Willd.): composition, chemistry, nutritional, and functional properties. Advances in Food and Nutrition Research, 58, 1-31.

Abugoch, L. E., Romero, N., Tapia, C. A., Silva, J., \& Rivera, M. (2008). Study of some physicochemical and functional properties of quinoa (Chenopodium quinoa Willd) protein isolates. Journal of Agricultural and Food Chemistry, 56(12), 4745-4750.

Aluko, R. E., \& Monu, E. (2003). Functional and bioactive properties of quinoa seed protein hydrolysates. Journal of Food Science, 68(4), $1254-1258$

Ando, H., Chen, Y.-C., Tang, H., Shimizu, M., Watanabe, K., \& Mitsunaga, T. (2002). Food components in fractions of quinoa seed. Food Science and Technology Research, 8(1), 80-84.

Aora, J. C. C., \& Alvarado, K. (2009). Aislados proteínicos de granos altoandinos chenopodiaceas; quinua "chenopodium quinoa"cañahua "chenopodium pallidicaule" por precipitación isoeléctrica. Revista Boliviana de Quimica, 26(1), 12-20.

Arakawa, T., \& Timasheff, S. N. (1982). Preferential interactions of proteins with salts in concentrated solutions. Biochemistry, 21(25), 6545-6552.

Avila Ruiz, G., Opazo-Navarrete, M., Meurs, M., Minor, M., Sala, G., van Boekel, M., et al. (2016a). Denaturation and in vitro gastric digestion of heat-treated quinoa protein isolates obtained at various extraction pH. Plant Foods for Human Nutrition. doi:10.1007/ s11483-016-9429-4.

Avila Ruiz, G., Xiao, W., van Boekel, M., Minor, M., \& Stieger, M. (2016b). Effect of extraction $\mathrm{pH}$ on heat-induced aggregation, gelation and microstructure of protein from sweet quinoa (Chenopodium quinoa Willd) Food Chemistry. doi:10.1016/j.foodchem.2016.04. 052.

Bhargava, A., \& Srivastava, S. (2013). Chemistry. In A. Bhargava \& S. Srivastava (Eds.), Quinoa - Botany, Production and Uses (pp. 185239). Oxfordshire: CABI.

Brinegar, C., \& Goundan, S. (1993). Isolation and characterization of chenopodin, the 118 seed storage protein of quinoa (Chenopodium quinoa). Journal of Agricultural and Food Chemistry, 41(2), 182185

Brinegar, C., Sine, B., \& Nwokocha, L. (1996). High-cysteine 2S seed storage proteins from quinoa (Chenopodium quinoa). Journal of Agricultural and Food Chemistry, 44(7), 1621-1623.
Chauhan, G. S., Eskin, N. A. M., \& Tkachuk, R. (1992). Nutrients and antinutrients in quinoa seed. Cereal Chemistry, 69, 85-88.

Chauhan, G. S., Cui, W., \& Eskin, N. A. M. (1999). Effect of saponin on the surface properties of quinoa proteins. International Journal of Food Properties, 2(1), 13-22.

Collins, K. D. (1997). Charge density-dependent strength of hydration and biological structure. Biophysical Journal, 72(1), 65-76.

Föste, M., Elgeti, D., Brunner, A.-K., Jekle, M., \& Becker, T. (2015). Isolation of quinoa protein by milling fractionation and solvent extraction. Food and Bioproducts Processing, 96, 20-26.

Li, W., \& Mu, Y. (2011). Hydration patterns and salting effects in sodium chloride solution. The Journal of Chemical Physics, 135(13), 134502.

Lindeboom, N. (2005). Studies on the characterization, biosynthesis and isolation of starch and protein from quinoa (Chenopodium quinoa Willd.). Ph.D. thesis, University of Saskatchewan, Canada.

Pelgrom, P. J. M., Vissers, A. M., Boom, R. M., \& Schutyser, M. A. I. (2013a). Dry fractionation for production of functional pea protein concentrates. Food Research International, 53(1), 232-239.

Pelgrom, P. M., Schutyser, M. I., \& Boom, R. (2013b). Thermomechanical morphology of peas and its relation to fracture behaviour. Food and Bioprocess Technology, 6(12), 3317-3325.

Pelgrom, P. J. M., Berghout, J. A. M., van der Goot, A. J., Boom, R. M., $\&$ Schutyser, M. A. I. (2014). Preparation of functional lupine protein fractions by dry separation. LWT-Food Science and Technology, 59(2, Part 1), 680-688.

Pelgrom, P. J. M., Boom, R. M., \& Schutyser, M. A. I. (2015a). Functional analysis of mildly refined fractions from yellow pea. Food Hydrocolloids, 44, 12-22.

Pelgrom, P. M., Boom, R., \& Schutyser, M. I. (2015b). Method development to increase protein enrichment during dry fractionation of starch-rich legumes. Food and Bioprocess Technology, 8(7), $1495-1502$.

Prego, I., Maldonado, S., \& Otegui, M. (1998). Seed structure and localization of reserves in Chenopodium quinoa. Annals of Botany, 82(4), $481-488$.

Scanlin, L., \& Stone M. (2009). Quinoa protein concentrate, production and functionality, Patent nr. US 7563473 B2.

Schutyser, M. A. I., \& van der Goot, A. J. (2011). The potential of dry fractionation processes for sustainable plant protein production. Trends in Food Science \& Technology, 22(4), 154-164.

Schutyser, M. A. I., Pelgrom, P. J. M., van der Goot, A. J., \& Boom, R. M. (2015). Dry fractionation for sustainable production of functional legume protein concentrates. Trends in Food Science \& Technology, 45(2), 327-335.

Suki, A., Fane, A. G., \& Fell, C. J. D. (1984). Flux decline in protein ultrafiltration. Journal of Membrane Science, 21(3), 269-283.

Tyler, R., Youngs, C. G., \& Sosulski, F. W. (1981). Air classification of legumes. I. Separation efficiency, yield, and composition of the starch and protein fractions. Cereal Chemistry, 58, 144-148.

Valenzuela, C., Abugoch, L., Tapia, C., \& Gamboa, A. (2013). Effect of alkaline extraction on the structure of the protein of quinoa (Chenopodium quinoa Willd.) and its influence on film formation. International Journal of Food Science and Technology, 48(4), 843849.

Wu, Y. V., \& Stringfellow, A. C. (1992). Air classification of flours from wheats with varying hardness: protein shifts. Cereal Chemistry, 69(2), 188-191. 